After consultation with their professional body pharmacists were individually canvassed by the director general of health to join the scheme, for which a management plan had been prepared. Specially designed equipment had been produced and was available from the outset.

Participating pharmacies order 20 exchange packs at a time, which are delivered in a purpose built cardboard box that doubles as the disposal unit. Each exchange pack consists of a cylindrical plastic container with screw top, ten $3 \mathrm{ml}$ syringes with 26 gauge needles attached, a packet of three condoms with illustrated instruction sheet, and a general information leaflet.

Pharmacists charge a service fee for selling the packs. This is less for a customer who returns the used equipment in the container (and who disposes of it personally through an opening into the cardboard box)

The scheme is coordinated nationally and locally from the equivalent of departments of community medicine or area health boards. In Northland the used exchange packs in their cardboard boxes are collected by the equivalent of environmental health officers and disposed of by incineration. A local directory leaflet that details all the outlets as well as local counselling services is distributed with each exchange pack. An answerphone gives a message with the same information.

Pharmacists have not had the problems with the scheme that some feared, and the scheme is operating well overall. Locally pharmacists have been trying to increase the return rate of used equipment and obtain a good geographical spread of pharmacy outlets. Over 400 packs are sold throughout New Zealand each week. The incidence of known HIV infection and AIDS in intravenous drug users is low (under $2 \%$ in both cases). Though it is too early to evaluate fully the scheme regarding its ultimate objective, the signs are quite encouraging.

Pharmacists participate voluntarily and more as a public service than a profit making venture. With that public spirit, a well thought out scheme nationally, and a will to make it succeed locally a similar scheme in England and Wales could successfully realise the role of community pharmacies in the prevention of AIDS among injecting drug misusers.

Northland Area Health Board

DAVID S G SLOAN

Whangarei,

New Zealan

1 Glanz A, Byrne C, Jackson P. Role of community pharmacies in prevention of AIDS among injecting drug misusers: findings of a survey in England and W'ales. Br.Med f 1989:299:1076-9. (28 Octobir.

\section{Radiography in women of childbearing ability}

SIR, - Dr Ruth Pearson's article concerning nonessential radiography in women of childbearing ability" describes the various reasons why the " 10 day rule" has largely been abandoned. If the 10 day rule is applied rigorously about $65 \%$ of this population are unavailable for routine radiological examinations at any given time. This would clearly cause considerable inconvenience for patients and medical and radiography staff, and Dr Pearson discusses the reasons why, in the light of current knowledge, this inconvenience is now felt to be unwarranted.

A new set of guidelines now seem necessary, but the suggestion that the 10 day rule be replaced by the "pregnancy question" ("Are you, or might you be, pregnant?") introduces a new order of uncertainty and confusion into the exercise of avoiding harmful irradiation of the fetus. Most women know whether or not they have had a period in the previous 10 days, but an appreciable proportion may easily be in the early stage of a pregnancy without realising it. Although the 10 day rule may have been unnecessarily restrictive and without sound biological basis, at least it was easy to comprehend and to apply in a busy clinic, accident department, or radiology suite. Perhaps a recommendation similar to but more convenient than the 10 dav rule would be more "user friendly." Dr Pearson states that exposure to diagnostic radiation during the first month of gestation now seems to carry negligible risk to the fetus. Why not then recommend a "four to five week rule." This would permit routine radiology in most young women (those who have a menstrual cycle of less than 35 days), greatly reducing the proportion whose investigation must be delayed, yet at the same time affording adequate protection to any potential fetus and being easy to apply.

NICHOI.AS M WILSON

St Thomas's Hospital

London SE1 7EH

1 Pearson R. Radiography in women of childbearing ability Br.Med f 1989:299:1175-6. (11 November.

SIR, - As a radiologist and service provider I am constantly aware of the need to audit users in other specialties. It is good to see that Messrs D I Wise and $\mathrm{R} J$ Cherry do the same in radiology, particularly when the topic concerns the possible harmful effects of irradiating fetuses.

The radiographer, who is the last person in the chain who may prevent this, must ask the patient, "Are you, or might you be, pregnant?" This is clearly stated in the guidelines issued jointly by the Royal College of Radiologists and College of Radiographers.' When contrast examinations are performed the radiologist has the same responsibility.

It is essential to realise, however, that responsibility is not solely that of the radiographers or radiologists but also that of the requesting clinicians. The guidance notes on ionising radiations clearly state that "the request form should state that the woman is or may be pregnant ...,", which implies that the referring clinician has asked the question about pregnancy.

Our largest group of non-inpatient referrals arriving for immediate $x$ ray examinations of the abdomen, pelvis, or lumbar spine come from orthopaedic clinics or casualty. Since the appearance of the paper by Messrs Wise and Cherry we have asked such women, when appropriate, whether the referring clinician asked about the possibility of pregnancy. We have yet to have one "yes." Neither has any suggestion of possible pregnancy been given on the request card.

If the guidelines are to be changed in future to protect ova from irradiation for seven weeks before ovulation' it seems totally inappropriate for radiographers to ask patients whether they are prepared to avoid pregnancy during these weeks unless patients have discussed pregnancy beforehand with the doctor concerned. Even with the 28 day rule, patients may be highly offended by inquiries outside the doctor-patient relationship about their fertility.

Far greater responsibility would then weigh on the shoulders of referring clinicians to ask the question about pregnancy, which, unfortunately, seems to have fallen somewhat by the wayside.

Department of Radiolugy.

JOHN HERBETKO

Southampton $\mathrm{S}(0)+\mathrm{X}$

1 Wise DI. Cherry RJ. Regional variations in policy on exposing women of childbearing age to ionising radiation. Br. Hed 1989:299: 1206. 11 November

College of Radiographers and Roval College of Radiologists. cinidelines for implementation of ASP'S. Exposure to iomsing

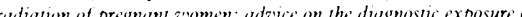

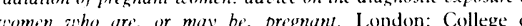
Radiograpers and Roval College of Radiologists, 1986.

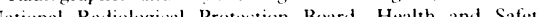

Executise, and Department of Health and Social Security (iuddance notes for the protection of persons against ionisin. radiations arising from medical and dental use. London: HMSO),

Baker TG, Neal P. Action of ionsing radiation in the mammalia warv. In: Zuckerman S, Weir BJ, eds. The ovar'. Vol l. New York: Academic Press, 1977:1-47.

\section{Psychology of limb loss}

SIR, - Though I agree with Mr A W G English that amputees must suffer from some psychological effects of losing a limb, it should be highlighted that serious medium or long term effects of "grief reaction," leading to inability to cope with the loss, are not very common. In general I have found that most recent amputees have lost their legs after a prolonged period of severe pain and restricted mobility. A large percentage of these are thankful and relieved to be rid of their painful and useless limbs.

Appreciable improvements in their physical and psychological state in the postoperative period are common. Furst and Humphrey suggested that delay between an accident and amputation can help patients and their partners to adapt to the loss, possibly through a process of anticipatory mourning. ' A similar process may also occur in patients with progressive diseases leading to amputation.

I agree with the suggestions of employing understanding and sensitivity when dealing with amputees and the benefit of trained counsellors, and they are already in practice in our unit. I strongly believe, however, that it is high time to look beyond the boundaries of the limb fitting centres. All personnel concerned with the management of amputation have very important parts to play in minimising the psychological and physical trauma and maximising the total rehabilitation of patients. Preoperative counselling to provide appropriate information; encourage participation of the patient in decision making about the level of amputation; and inform the patient of the surgeon's willingness to think beyond amputation, and therefore create the best possible stump at the most appropriate level, and about appropriate postoperative management would be an excellent start.

Proper assessment of and rapid provision of efficient prosthesis and physiotherapy of the highest possible quality, provision of efficient and effective wheelchairs, quick and efficient home adaptations, prompt rehousing when necessary, provision of various social outlets, and participation of the family in the rehabilitation process would all go a long way towards allowing amputees to cope with their physical and psychological loss.

We in Sheffield are about to start a project whereby amputee volunteers from our local amputee support group will be available on clinic days, on a rota basis, so that the more recen amputees get the opportunity, if they wish, to discuss and gather information on how others in similar circumstances have coped. We hope that this venture will help them cope with their disabilities.

Disablement Services Centre

Torthen General Hospital.

Sheffield S5 7 AT

1 English AW'(i. Pswchology of limb loss. Br.Med 7 1989;299:1287. 18 November.)

2 Furst L, Humphrey M Coping with loss of a leg. Prosthetics and Orthotics International 1983;7:152-6.

SIR, - The personal view by Mr A W G English, describing the counselling that has been set up in Roehampton for patients who have lost a limb, was encouraging.

I was disappointed, however, to read in the same issue an article by Mr Suresh Keetarut propounding the view that only in exceptional circumstances 
should a second prosthesis be provided. ${ }^{2} \mathrm{Mr}$ Keetarut describes a world seen only from the perspective of a professional, who despite his interviews with patients seems to have missed the opportunity to consider the provision of a spare limb from the perspective of amputees.

My sister in law has had a through knee amputation. She is under 30 and mother of an 18 month old child. Although she may be unusual in being young and having lost a limb, she is not exceptional. She has to travel $72 \mathrm{~km}$ to a limb centre; luckily she has her own transport. The waiting time at present for a new limb is three months. She has to have new joints every three months or so, as she wears them out quickly because she is quite active. Normally she wears one leg while the other is being repaired. At present, for the first time in eight vears, she has a spare limb at home. Before this if her leg failed she was restricted to crutches and in this state she could not even carry a cup of tea. The limb centre (which provides an excellen service) hopes to make limbs more quickly in the new year.

I do not see why my sister in law and others like her should be expected to cope without a spare limb. Surely people who are already disabled should be given the chance to maintain their indeperfdence if their usual prosthesis fails. Those who lose limbs as children and young adults have a difficult enough life coming to terms with their disability and the restrictions imposed by it. They certainly deserve a more caring and thoughtfu approach from the medical profession than that described by Mr Keetarut.

MERYL DEANE

leeds Eastern Health Authority.

Leeds LS7 3JX

1 English AW' (i. Psychology of limb loss. Br. .1ed f 1989:299:1287. 18 November.

Keetarut S. Spare artificial legs. Br Med f 1989;299:1260 (18 November.

\section{Women with Chlamydia trachomatis infection}

SIR,-Dr Lesley Southgate and colleagues point out the high prevalence of chlamydia in women in an inner city requesting a termination of pregnancy.' In south Manchester family planning clinics we saw 11732 women last year, covering fair cross section of the sexually active female population. We are able to take endocervical swabs for chlamydia culture at all our clinics, and we tend to take them together with most high vaginal swabs. Many swabs are taken in women with minor symptoms or signs, often after antifungal treatment.

In the past year $8 \%$ of the cultures $(65 / 817)$ were positive. At our local genitourinary medicine clinic the rate of positive cultures in the first six months of 1989 was $10 \%$.

All patients with positive swabs are recalled to the clinic and referred to a genitourinary medicine clinic after the importance of adequate treatment and follow up for themselves and for their partners has been explained. We find that most patients attend these clinics and that the stigma is not problem if explanation of the need for the visit is adequate.

Chlamydia is a major cause of symptomatic and asymptomatic pelvic infection and subsequent infertility. We emphasise the need for the primary health carers to be aware of its prevalence and treatment and the need for adequate follow up.

Family Planning Centre

ANNE M C WEBB

Manchester $11209 \mathrm{LJ}$

$S$ CHANDIOK

Department of Genitourinary Medicine,

University Hospital of South Manchester.

Manchester M20 8L.R
1 Southgate L, Treharne J, Williams R. Detection, treatment and follow up of women with Chlamydia trachomatis infection seeking abortion in inner city general practices. $\mathrm{Br} \mathrm{Med} 7$ 1989;299:1136-7. (4 November.)

SIR,-We are surprised that Dr Lesley Southgate and colleagues failed to detect Mycoplasma hominis in cervical or vaginal swabs taken from women requesting abortion.' $M$ hominis is a common inhabitant of the vagina and is recognised to be an important cause of pelvic inflammatory disease. ${ }^{2}$ We recently undertook a small study of cervical flora in 37 patients requesting termination of pregnancy. Chlamydia trachomatis was detected in three patients $(8 \%)$ and $M$ hominis in six $(16 \%)$. These figures are similar to the findings of a study by Ridgeway et al in 1983. ${ }^{3}$

We suggest that preoperative or perioperative antimicrobial prophylaxis for planned termination of pregnancy should use an agent such as tetracycline that is active against both these common pathogens.

ROSAMOND A COX

Kettering and District General Hospital, MICHAEL CRICK Kettering NN16 8UZ

I Southgate L, Treharne J, Williams R. Detection, treatment, and follow up of women with Chlamydia trachomatis infection seeking abortion in inner city general practices. Br Med $f$ 1989;299:1136-7. (4 November.)

2 Mardh PA, Westrom L. Tubal and cervical cultures in acute salpingitis with special reference to Mycoplasma hominis and T-strain mycoplasmas. Br f Vener Dis 1970;46:179-86.

3 Ridgeway GL, Mumtaz G, Stephens RA, Oriel JD. Therapeutic abortion and chlamydial infection. Br Med $\mathcal{F}$ 1983;286: 1478-9.

\section{Gall bladder lithotripsy}

SIR,-We fully appreciate the objectives and considered wisdom of the sentiments expressed by $\mathrm{Dr}$ Gillian Matthews in her editorial on gall bladder lithotripsy' but nevertheless think that they are detached and perhaps a little inconsiderate to patients, and they deserve some response. A bureaucratic approach on the lines of $\mathrm{Dr}$ Matthews's article might lead to stagnation in this field of development and even to the loss of new technologies that may later prove to be of value.

If $\mathrm{Dr}$ Matthews was to take, for example, cholecystectomy and subject it to the same scrutiny, it too might not get off the drawing board. She accepts this treatment as optimum for symptomatic gall stones but omits to recognise its drawbacks. After 100 years or more we have learned that cholecystectomy, though satisfactory in many cases, is not always an ideal treatmentnot least because of the discomfort and costs involved but also because there are other problems such as morbidity, mortality, and long term symptoms that may occur after surgery. ${ }^{2}$ In response to these problems many new remedies for symptomatic gall stones are being developed; different forms of treatment will apply to different situations. If we progress at the rate implied in this review then the answers to various problems will not come for many years.

Lithotripsy for gall stones would not have reached its present stage of development had not the technology already been developed for kidney stones. ${ }^{3+}$ Managing gall stones is much more complex because additional treatment is needed for dissolution. ${ }^{5}$ The treatment works for some people with gall stones and is sought after because it is essentially painless - a point that was omitted by Dr Matthews.

This may not yet be the time for gall stone lithotripsy. We are perhaps still at the stage of phase studies. For example, when lithotripsy is compared with cholecystectomy ${ }^{6}$ an inaccurate assessment of lithotripsy may result either because the wrong lithotripter was used or because the lithotripter was not used to its best effect, or even because of the use of a suboptimal form of dissolution therapy.

We are extremely concerned about the philosophy of many companies marketing lithotripsy machines. The selling of machines by some companies far overrides their desire for critical evaluation of the application of their product. This point has to be grasped firmly and responsibly by clinicians, who must not become lapdogs to commercial interests or they will abrogate their right to assess new technologies. This will not in the long term be good for our patients.

F B V KEANE

Department of Surgery,

Meath Hospital,

Dublin 8 ,

Ireland

Matthews G. Gall bladder lithotripsy. Br Med f 1989;299:1060-1 (28 October.)

2 Ros E, Zambon D. Post cholecystectomy symptoms. A prospective study of gallstone patients before and two years after tive study of gallstone paticnt

3 Sackman, M, Delius M, Sauerbruch T, et al. Shock wave lithotripsy of gallstones. The first 175 patients. $N$ Engl $f . M e d$ lithotripsy of gals

4 Darzi A, Monson JR'T, O'Morain C, Tanner WA, Keane FBV. Darzi A, Monson JR'T, O'Morain C, Tanner WA, Keane FBV.
Extension of selection criteria for extracorporeal shock wave lithotripsy for gall stones. Br Med f 1989;299:302-3.

Darzi A, Leahy A, O'Morain C, Tanner WA, Keane FBV Randomised controlled study to compare treatment of gallstones by chemical dissolution and extracorporeal shock wave lithotripsy either alone or in combination. Gut 1989;30:A 1459.

6 Milner DC, Nicholl J, Westlake L, et al. The design of a randomised controlled trial for the evaluation of lithotripsy as a treatment for gallstones. Fournal of Lithotripsy and Ston Disease 1989;1:122-32.

\section{Consent and people with mental handicap}

SIR,-Professor Joan Bicknell's editorial on consent and people with mental handicap provides a timely reminder of a situation about which many doctors seem to be unaware.' After the introduction of the 1983 Mental Health Act it became more generally appreciated that no one can give consent on behalf of a mentally handicapped person. As a result, this hospital developed two "operation acknowledgement forms," one to be signed by relatives and one by a medical officer, to be used when the subject is unable to give real consent.

The important features of the forms are that the notion of consent is avoided in the title, that the signatory "understands the necessity for the operation," and the recognition of the fact that any consent given elsewhere has no legal validity. In other ways the documents are similar to the familiar consent forms, with escape clauses with regard to further or alternative measures that may be found necessary, a disclaimer that any particular practitioner will perform the operation, and a separate clause where the doctor who has explained the operation provides a signature to that effect. The medical officer's form additionally requires the doctor to explain why the subject is unable to give real consent.

The draft code of practice in the 1983 Mental Health Act recommends that before surgical treatment the surgeon, if possible with the subject's permission, involves relatives or friends and consults with relevant colleagues and makes a record of these discussions. The Medical Defence Union echoed these cautions but had no objection to our forms provided that they were accepted by the health authority and the medical staff concerned.

The operation acknowledgement forms have been in use for a number of years at two local general hospitals without major problems. They may be seen by some to smack of paternalism, but they have the overriding virtue of providing objective evidence that a relative or carer not only has participated in the decision to operate but also understands why it has been made. This has great 